\title{
Occupational noise exposure among the workers of Kerman Cement Plant, 2009
}

\author{
Ghotbi Ravandi MR, $\mathrm{PhD}^{1}$, Nadri F, MSc ${ }^{2}$, Khanjani N, $\mathrm{PhD}^{3 *}$, Ahmadian M, MSc ${ }^{4}$ \\ 1- Assistant Prof., Dept. of Occupational Health, School of Public Health, Kerman University of Medical Sciences, \\ Kerman, Iran. 2- Master of Occupational Health, School of Public Health, Kerman University of Medical Sciences, \\ Kerman, Iran. 3- Assistant Prof. Dept. Epidemiology and Statistics, Kerman University of Medical Sciences, Kerman, \\ Iran. 4. Faculty member, Social development \& Health promotion Research Center, Kermanshah University of Medical \\ Sciences, Kermanshah, Iran.
}

\begin{abstract}
Received: August 2011, Accepted: November 2011

Background: The sound is an environmental and occupational pollutant and can cause a number of reactions in human body, in which hearing loss is one of the most important effects. Cement industry is one of the industries with noise induced hazards. The aim of this study was to evaluate the noise level in different parts of Kerman Cement Plant.

Materials and Methods: This descriptive cross-sectional study was done in Kerman Cement Plant in 2009. The sound level was measured according to the standard ISO 9612:1997 (E) in workers main commuting spots. Noise levels were measured by the testo SLM device (Model CEL-815) in network A and calibrator model IEC942/90 claa2. Data were analyzed by the EXCEL software.

Results: The highest sound pressure level in the Cement Plant $(106 \mathrm{db})$ was recorded in the stone crushing units and the grinding units (mills); 14 units had a mean sound level above the permissible $85 \mathrm{db}$ noise level.

Conclusion: There are specific units with high noise exposure in the Kerman Cement plant. Thus systematic noise evaluation in the working units, worker education, noise control, distributing proper standard noise protection equipment among the workers, performing annual audiometries, and evaluating and updating noise control programs are necessary.
\end{abstract}

Key Words: Cement Plant, Noise level, Noise Pollution, Kerman

\section{Introduction}

High noise levels have been recognized as a threat to the human health for many centuries. In the past only a small group of people were exposed to the harmful effects of noise, but after world war II due to rapid industrialization and the increase in noise producing sources worldwide, ordinary people also became exposed to the harmful effects of high noise levels [1]. High occupational noise exposure is still an essential health hazard worldwide; for example, in the USA more than 30 million workers are exposed to dangerous noise levels. Also in Germany 4 to 5 million people
(12 to $15 \%$ of the workforce) are exposed to noises which are classified dangerous by the WHO [2]. In America more than 5 million workers are exposed to noises higher than 85 $\mathrm{db}$ in their working environments [3]. The negative effects of noise on humans include physiological and psychological effects; the most important physiological effect of noise on the human body is hearing loss [4]. Its physiological effects are more prevalent than the psychological effects which are stress,

\footnotetext{
Corresponding Author: Naeges Khanjani, Dept. Epidemiology and Statistics, Kerman University of Medical Sciences, Kerman, Iran.

Email: n_khanjani@kmu.ac.ir
} 
anger, distraction, lack of concentration and decreased cognition [5]. Among the other physiological effects of noise on human is the increased blood pressure [6, 7] and eventually cardiovascular diseases which account for a high percentage of work related diseases [8]. Noise is a factor for inducing stress related reactions. Stress increases the probability of cardiovascular diseases. In some studies, noise has been classified as the second external factor for coronary artery diseases after smoking $[9,10]$.

The cement plant is one of the noisiest working environments. Several studies in Iran [11-13] and other countries [14, 15] have reported high noise exposure in different industries, however few [14] have focused on cement factories. The harmful effects of noise depend on the type of industry, the plant section and the exposure intensity, and duration of the workers' shifts [7]. Kerman Cement plant is located approximately $15 \mathrm{~km}$, on the south west of Kerman, a city in the south east of Iran [16]. The plant is located on the way to Bandar Abbas and is one of the main cement exporters of the Persian Gulf region. This plant was launched on August 3, 1967 [17]. In this plant raw materials, which consist mainly of lime-stone, silica, alumina and iron materials, after complete grinding and mixing, are heated up to $1600^{\circ} \mathrm{C}$ in a rotary kiln to produce cement [16]. This factory has three production lines, Which produces more than 3500 tons cement per day. The products of this plant are type 1 cement (natural pozzolan), type 2 (Portland), type 5 (Portland), HSR and G class (used for oil expeditions) [17]. This plant has employed more than 900 people of which less than 400 are working in the noisy units. The cement manufacturing process consists of four processing steps: crushing of raw materials, grinding of raw materials, pyroprocessing, and grinding of clinker and packing. The whole process is associated with high noise levels due to the striking, loading and transportation of the rocks, clinker and steel balls, the traction systems of the mills and the fans and blowers for the transport of gasses and materials [18]. The aim of this study was to measure the average noise pollution in different parts of Kerman Cement Plant. The measurements will help us to estimate the average noise exposure of workers in the different units of this industry. It will also provide the essential data for spatial noise mapping and planning efficient noise control and hearing protection programs in different units of this factory. The data can also be used for forecasting and planning control programs in the newly established cement factorie, in which sufficient data has not yet been accumulated for action.

\section{Materials and Methods}

This study was a descriptive cross-sectional study done in Kerman Cement Plant in 2009. The map of different parts of the plant was inquired and the stations for noise measurement were selected from the places which workers used to stop or commute more than other places. the selection and measurement of noise in all units of the cement plant was done according to ISO 9612:1997(E).

The level of noise was measured by an occupational health specialist who was familiar with the measuring device instructions and the study protocol. All measurements were done during morning work hours (from 6 am to $2 \mathrm{pm}$ ) in which the maximum number of workers were working, and all of the noise producing equipment were operating. The noise produced in different units was different and depended on the unit's surface $\left(\mathrm{m}^{2}\right)$, number of operating 
equipment, number of people working and the type of work. The number of our measurements depended on the unit's surface, and more measurements were done in larger halls. The factory units, number of people working and the $\mathrm{db}$ in each measuring station was recorded. Noise was measured in a sum of 224 measurement stations. In each station at least 3 measurements were done and the logarithmic mean for each station was determined. In this Factory, workers work in 8 hour shifts and the sum of noise exposure in each shift is about 6 hours. In order to measure noise levels, the testo SLM devise (model CEL-815) in the A network was used and for calibrating it the calibrator model Testo IEC942/90 claa2 was used.
For measuring noise, the noise meter microphone had at least one meter distance from reflective surfaces such as walls or machinery and its distance from the floor was about 5 feet or 1.5 meters. Data about noise levels were gathered in each unit, and the logarithmic means were calculated for each unit. The statistical analysis was done by EXCEL software and the units that had noise levels higher than the standard threshold (85db) were determined.

\section{Results}

The map and the measurements in one of the working halls as a sample has been shown in figure 1 .

Figure1: the noise measurement stations of one working hall

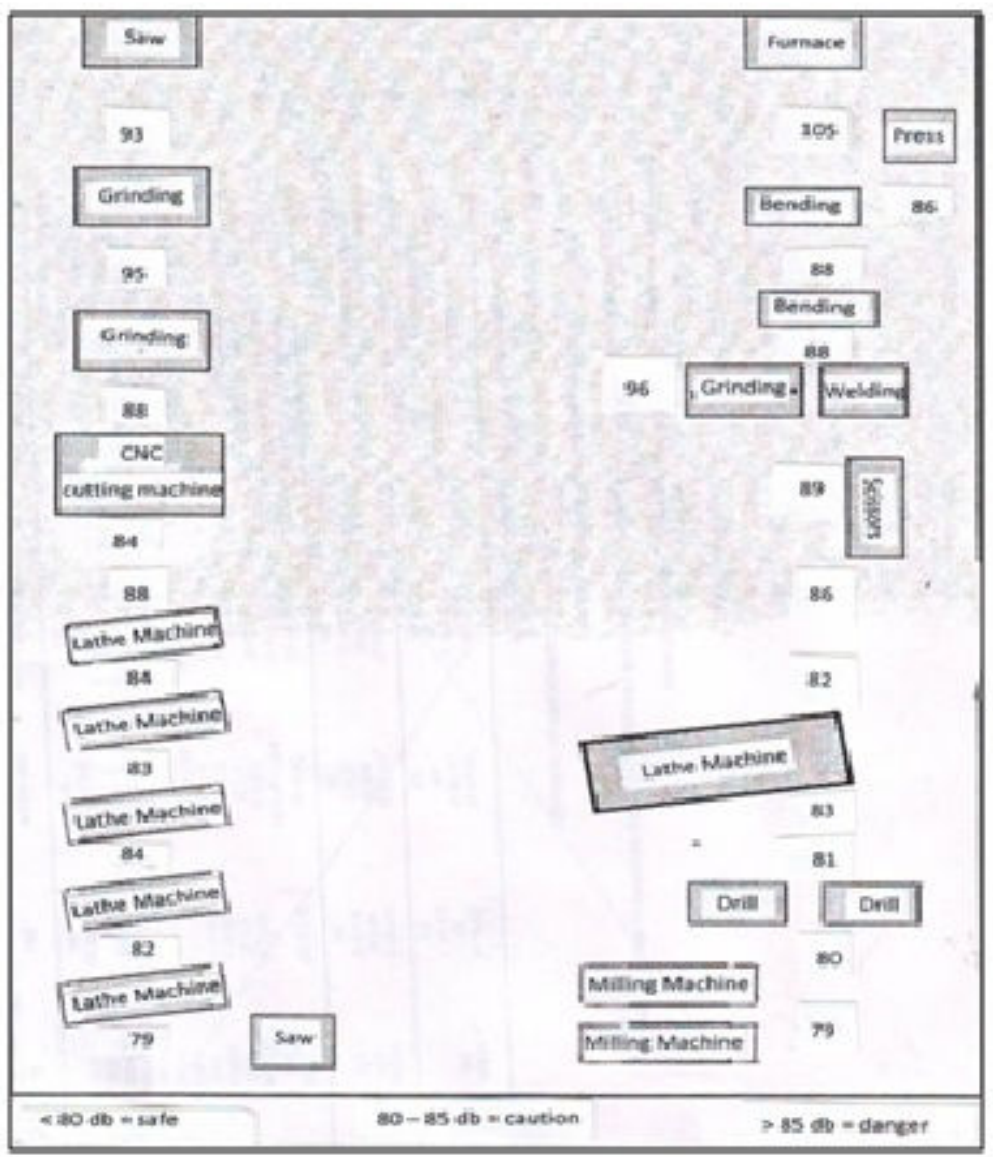


Table 1: The noisy units of Kerman Cement Factory, the mean, maximum and minimum of noise measured $(\mathrm{db})$ and number of workers in each unit.

\begin{tabular}{lcccc}
\hline Unit name & Mean \pm SD (db) & Min - Max (db) & $\begin{array}{c}\text { Number of } \\
\text { workers }\end{array}$ & $\begin{array}{c}\text { No. of noise } \\
\text { measurement stations }\end{array}$ \\
\hline Raw material mill & $100.1 \pm 1.3 *$ & $98-102$ & 22 & 16 \\
Cement mill & $99.4 \pm 1.6 *$ & $96-102$ & 30 & 16 \\
Gypsum mill & $99.4 \pm 1.6 *$ & $96-102$ & 3 & 16 \\
Iron ore mill & $100.1 \pm 1.3 *$ & $98-102$ & 3 & 16 \\
Crusher & $103.5 \pm 1.3 *$ & $102-106$ & 8 & 10 \\
Preheater & $80 \pm 0.9$ & $79-81$ & 6 & 6 \\
Furnaces & $94 \pm 8.8 *$ & $84-106$ & 31 & 6 \\
Prefurnace group repair & $84.3 \pm 4.7$ & $77-92$ & 18 & 4 \\
Soil silo & $80.8 \pm 1.3$ & $79-82$ & 5 & 4 \\
Klinger storage & $84.1 \pm 3.5$ & $79-88$ & 3 & 4 \\
Tonnage house & $82 \pm 3.7$ & $78-88$ & 3 & 6 \\
Repair of tonnage house & $93 \pm 5.8 *$ & $86-105$ & 14 & 6 \\
Operations group & $76.6 \pm 3.4$ & $72-82$ & 26 & 6 \\
Building Department & $81 \pm 4.2$ & $75-86$ & 15 & 8 \\
Laboratory group & $74.4 \pm 3$ & $70-78$ & 21 & 6 \\
Power (Electricity) & $81 \pm 6$ & $72-88$ & 68 & 4 \\
Electrostatic Filter & $98.4 \pm 1.5 *$ & $97-101$ & 12 & 12 \\
Casting & $89.7 \pm 3.9 *$ & $85-95$ & 2 & 6 \\
Technical Service Group & $91.8 \pm 5 *$ & $86-100$ & 13 & 6 \\
Technical Project Office & $73.2 \pm 2.7$ & $70-77$ & 15 & 22 \\
Technical Workshop & $88.3 \pm 6.5 *$ & $79-105$ & 38 & 6 \\
Furnace repair group & $78.2 \pm 6.1$ & $75-89$ & 13 & 5 \\
Mechanics & $86.8 \pm 7.7 *$ & $77-101$ & 22 & 13 \\
Vehicle repair shop & $88.5 \pm 7.3 *$ & $77-102$ & 12 & \\
Power plant & $91.2 \pm 6.3 *$ & $84-106$ & & \\
\hline
\end{tabular}

* Noise above national recommended level

After collecting the measurements, in all of these halls the logarithmic average and the standard deviation of noise intensity were calculated. The results of noise measurement, the number of people working in each unit and the number of noise measurements done in each unit have been shown in table 1 .

Kerman Cement Plant has a total of 29 units and the units that have a higher noise level have been shown in table 1 . The results showed that from a total of 29 units operating in the Kerman Cement Factory, 14 units have noise levels above $85 \mathrm{db}$ which noise control programs should be executed in them. The range of noise level in different parts of the plant was from 39 to $106 \mathrm{dBA}$. As it has been shown in the table 1 , among the units with noise levels, more than $85 \mathrm{db}$, the iron ore mill, crushing and the raw material mills had the highest average noise levels.

\section{Discussion}

The present study showed that the Cement Plant due to its high noise exposure is among the hazardous industries and noise exposure in some parts of Kerman plant has reached dangerous levels of up to $106 \mathrm{db}$. According to the safety standards in this high noise intensity, the exposure time should be shortened (Table 2).

Also the necessity of frequent noise evaluation, machinery control and maintenance in the working environments should be highlighted. It has been mentioned in numerous sources that noise intensities 
similar to the ones measured in this plant can lead to hearing loss [19]. According to the estimates of the American Occupational Health and Safety Institute, from every four workers aged above 55 years and exposed to noise levels above $90 \mathrm{db}$, one has hearing difficulties. This institute describes noise induced hearing loss as one of the 10 important occupation related diseases [19].

A study from a cement plant in Holcin, Croatia reported that most of the machinery produce noise levels between 67 to $112 \mathrm{db}$ in one meter distance [18].

Another study conducted by the Workers' Health Center of one cement plant in Brazil, showed that noise and temperature were the most important hazardous exposures in these workers and the noise levels were up to about $120 \mathrm{db}$ [20]. In our study, the minimum measured noise level was $39 \mathrm{db}$ and the maximum was $106 \mathrm{db}$. This higher noise level at the cement industry in comparison to other industries is probably related to the work structure and type of operations performed at these factories. Similar studies from other researchers, such as the study done by Golmohammadi et al showed that environmental noise levels at the Isfahan Iron Melting Plant were between 75 to $105 \mathrm{dBA}$ [12].

In another study of construction industry the average measured noise levels in a cement mason were $79.3 \mathrm{dBA}$ and more than half of the measurements were above the $85 \mathrm{dBA}$ standard threshold and in 10 cases it was more than $90 \mathrm{db}$ [21]. Bostani et al studies done in 23 functional units of the Abadan Oil Refinery showed that the minimum average noise exposure in these units was $83 \mathrm{db}$ and the maximum was $102.1 \mathrm{db}$ [11] and Jahangiri and Adl's study in the Imax Unit of the Tehran Oil Refinery showed that the noise level in this unit is higher than the standard recommended level ( $85 \mathrm{db})$ [22]. In another study about the noise exposure of construction workers, results showed that the noise exposure in this occupation is also at a level that can cause harmful effects for the workers hearing and had reached about 87 $\mathrm{db}$. In this study out of 60 construction workers whom did an audiometery, 45 workers used ear muffs during work, but the hearing loss detected in workers showed that the hearing protection program was not efficient [23].

There are also studies that show the hearing protection gear used in some industries is not efficient either [11]. Therefore, it is essential to have occupational hygienists' supervision over choosing and correct using of hearing protection equipments in different industries. Other studies measuring noise levels in cement factories and evaluating the workers hearing loss in these factories have shown that $55 \%$ of the workers had levels of noise induced hearing loss [14]. In our study among the units with noise levels more than $85 \mathrm{db}$, the iron ore mill, crushing and the raw material mill had the highest average noise levels. Because of the high number of workers that operate in units with high noise pollution (table 1); noise control, the use of personal hearing protection equipment, reduction in working times and other preventive strategies are necessary in Kerman Cement Plant.

The time restrains that should be applied accordingly in case of high noise levels based on international standards has been shown in table 2. Kerman Cement Factory is one of the major Iranian industries with high industrial hygiene standards. All of the workers in the noisy industrial units are equipped with ear plugs, and are screened annually for work related disease and hearing loss. Nevertheless, the factory's privacy regulations did not allow us to access workers' health files. 
Table2: The standard duration of noise exposure according to National and ACGIH Standards

\begin{tabular}{ccc}
\hline Noise Intensity & Duration of Exposure \\
\hline $\mathbf{8 2}$ & $\mathbf{d b}$ & 16 hours \\
$\mathbf{8 5}$ & $\mathbf{d b}$ & 8 hours \\
$\mathbf{8 8}$ & $\mathbf{d b}$ & 4 hours \\
$\mathbf{9 1}$ & $\mathbf{d b}$ & 2 hours \\
$\mathbf{9 4}$ & $\mathbf{d b}$ & 1 hour \\
$\mathbf{9 7}$ & $\mathbf{d b}$ & $30 \mathrm{~min}$ \\
$\mathbf{1 0 0}$ & $\mathbf{d b}$ & $15 \mathrm{~min}$ \\
$\mathbf{1 0 3}$ & $\mathbf{d b}$ & $7.5 \mathrm{~min}$ \\
$\mathbf{1 0 6}$ & $\mathbf{d b}$ & $3.75 \mathrm{~min}$ \\
\hline
\end{tabular}

Another study stated that among the units in a cement factory the coal mill, Kiln/Raw mill, packers of cement plant and DG sets had the highest noise production [24].

The noise pollution control measures proposed for cement plants are provision of acoustic dampeners in foundations and insulators in the interiors, encasement of noise generating equipment, development of a thick greenbelt all around the plant boundary to act as a noise attenuator, providing ear muffs to personnel working near high noise levels, providing suitable acoustic barriers around areas generating high noise, and effective preventive maintenance and vibration measurements of all rotating equipments [24]. Application of noise mapping techniques in complex industrial environments such as the cement plant shows that with reliable acoustic and spatial data, proper noise map and action planning can be calculated. Obviously, without acoustic measurements or reliable databases it is not possible to noise map the industrial source [18].

All hearing protection devices should be labeled with a Noise Reduction Rating, which is an estimate of how much noise the protector will block. Typically, this level should be about two times higher than the protection most workers experience in actual use [21].

\section{Conclusion}

According to the results of this study and other studies, the cement plant is one of the industries with high noise exposure and a multiple step noise control program including noise evaluation, worker education, engineering strategies for noise reduction, determining the hazardous zones, distributing standard hearing protection devices, annual audiometries and evaluation and revision of noise control programs should be implemented.

\section{Acknowledgement}

This study was approved by the Environmental Medical Research Committee and was supported by a grant from the Deputy of Research, Kerman Medical University. The authors acknowledge Kerman Cement Plant for its full cooperation in conducting this study.

Conflict of interest: Non declared

\section{References}

1. Celik O, Yalcin S, Ozturk A. Hearing parameters in noise exposed industrial workers. Auris Nasus Larynx 1998; 25(4):369-75.

2. Concha-Barrientos M, Campbell-Lendrum D, Steenland K. Occupational noise: assessing the burden of diseases from work-related hearing impairment at national and local levels. Protection of the Human Environment. Geneva: World Health Organization 2004.

3. Dobie RA. Industrial audiometry and the otologist. Laryngoscope 1985; 95(4):382-5.

4. Melamed S, Fried Y, Froom P. The interactive effect of chronic exposure to noise and job complexity on changes in blood pressure and job satisfaction: a longitudunal study of industrial employees. J Occup Health Psychol 2001; 6(3):182-95.

5. Atmaca E, Peker I, Altin A. Industrial noise and its effects on humans. Polish Journal of Environmental Studies 2005; 14(6):721-6.

6. Brattico E, Kujala T, Tervaniemi M, Alku P, 
Ambrosi L, Monitilloe V. Long-term exposure to occupational noise alters the cortical orginization of sound processing. Clin Neurophysiol 2005; 116(1):190-203

7. Iyawe VI, Ebomoyi IE, Chiwuzie JC, Alakija W. Some factors which may affect blood pressure in Nigerian cement factory workers. Afr J Biomed Res 2000; 3:117-21.

8. Price AE. Heart disease and work. Heart 2004; 90(9):1077-84.

9. Ising H, Babisch w, Gunther T. Work noise as a risk factor in myocardial infarction. Journal of Clinical and Basic Cardiology 1992; 2(1):64-8.

10. Hilt BMD, Romyhr TQO. Morbidity from ischemic heart disease in workers at a stainless steel welding factory. Nor Epidemiol 1999; 9(1):21-6.

11. Bostani MR, Mazarei R. Noise pollution and its control in the Abadan refinery. Presented at the first national noise conference, Mashhad, Iran, February 21- 22, 2004. [Persian].

12. Golmohammadi R, Zamanparvar A, Khalili SA. The relation between noise and hearning loss in the workers of Esfahan Iron Melting Factory. Journal of Hamadan University of Medical Sciences 2001; 8:35-8. [Persian]

13. Halvani GH, Zare M, Barkhordari A. Noise induced hearing loss among textile workers of Taban factories in Yazd. The Scientific Journal of Birjand Medical School 2009; 4(15(series 37)):6974. [Persian]

14. Hernandez-Gaytan SI, Santos-Burgoa C, BeckerMeyer JP, Macias-Carrillo C, Lopez-Cervantes M. Prevalence of hearing loss and correlated factors in cement plant. Salud Publica Mex 2000; 42(2):10611.

15. Neitzel R, Seixas N. The effectiveness of hearing protection among construction workers. J Occup Environ Hyg 2005; 2(4):227-38.

16. Baroutian S, Mohebbi A, Soltani Goharrizi AS.
Measuring and modeling particulate dispersion: a case study of Kerman Cement Plant. J Hazard Mater 2006; 136(3):468-74.

17. History of the Kerman Cement Plant. Kerman Cement Industries Inc.; 2011 [updated 2011; cited Oct 7, 2011]; Available from: www.kermancement.com.

18. Stimac A. The application of the noise mapping technique in the comples industrial environment. Presented at the second congress of Alps-Adria Acoustics Association and the first congress of Acoustical Society of Croatia, Acoustical Society of Croatia, Opatija, Croatia, June 23-24, 2005. p 195-202.

19. Aghilinezhad M Mostafaei M (2000). Occupational Medicine and Occupational Diseases. $2^{\text {nd }}$ ed. Tehran: Arjomand Publications.

20. Quiros L, Gonzalez Webb A. Assessment of cement dust concentrations and noise levels in a cement plant in Nicaragua: School of Public Health, UCB; 2005.

21. Construction Industry Noise Exposures, Cement Masons: Department of Environmental and Occupational Health Sciences, School of Public Health and Community Medicine, University of Washington; 2004.

22. Jahangiri M, Adl J. Human errors made from the interaction of noise and human reactions in the isomax unit of Tehran refinery. Presented at the the first national noise conference, Mashhad, Iran, February 21-22, 2004;.

23. Marcos D, Quintana FS, Chavarra N, Ballesteros JA. Noise exposure of workers of the construction sector. Applied Acoustics. 2009; 70:753-60.

24. Jaiprakash Associates Ltd, Executive Summary of proposed cement plant (Clinker production: 2.05 MTPA, Cement production: 2.54 MTPA) at Baga Village, Arki Tahsil, Solan District, Himachal Pradesh; 2004. 